\title{
EXPERIMENTAL INVESTIGATIONS OF VEGETABLE \& MINERAL OIL PERFORMANCE DURING MACHINING OF EN-31 STEEL WITH MINIMUM QUANTITY LUBRICATION
}

\author{
Gurpreet Singh $^{1}$, Sehijpal Singh ${ }^{2}$, Manjot Singh $^{3}$, Ajay Kumar ${ }^{4}$ \\ ${ }^{1,4}$ Lecturer, Department of Mechanical Engineering, Rayat Polytechnic College, Rail Majra, S.B.S Nagar, Punjab, India, \\ ${ }^{2}$ Prof. and Head, Department of Mechanical Engineering, ${ }^{3}$ M. Tech Student in Department of Production Engineering, \\ Guru Nanak Dev Engineering College, Ludhiana, Punjab, India, \\ gssingh410@gmail.com,mech@gndec.ac.in,manjotbawag27@gmail.com,eraj_sharma@rediffmail.com
}

\begin{abstract}
Machining with Conventional flood lubrication is a common practice in the industries for reducing friction, heat and cutting power. The type of cutting fluid used during machining play important role in enhancing the machining performance if and only if it is selected, applied, handled and disposed in better way. Cutting fluids often poses hazard to man, environment, machine and material. It sometimes also becomes uneconomical; when application method, flow rate and cost of cutting fluid are remain unattended or underestimated. In Conventional flood lubrication a large quantity of lubricant is applied continuously at the tool chip interface does not remove heat effectively as much required because of poor penetration and obstruction from the chip. Therefore this system is becoming uneconomical for machining and unsuitable for environment. On the other hand wastage disposal of this large quantity of cutting fluid (petroleum based) is becoming problematic. Therefore the present study has been conducted by Vegetable based Minimum quantity Lubrication to reduce or to minimize hazards caused by Conventional flood lubrication. The Results of surface roughness obtained during Turning of EN-31 Steel with Minimum quantity lubrication of both mineral oil and vegetable are compared with each other and indicates that the surface roughness of vegetable oil is close proximity with mineral oil.
\end{abstract}

Index Terms: Minimum quantity lubrication (MQL), Vegetable oil, Mineral oil, Surface roughness, EN-31 Steel

\section{INTRODUCTION}

During Metal cutting operation heat is generated at tool chip interface because of friction. This generated heat affects the machining performance in terms of surface finish, dimensional accuracy, tool life and machining cost. Different Techniques have been utilized to minimize this heat. Water was used as a coolant to reduce this heat in the beginning, but it causes problem like corrosion. On the development of Technology the different Cooling and lubrication techniques have been come into existence. The Flood lubrication has been the mostly commonly used in industries for cooling and lubrication purpose. In this techniques cutting fluid is supplied continuously having flow rate up to $3-10 \mathrm{l} / \mathrm{min}$. There are different cutting fluid and cooling techniques for different metal cutting operations because of different cutting mechanism. Cutting fluids not only improve the machining performance but also help to facilitate chip flushing. The basic function of metal working fluid as a coolant to decrease the chip tool interface temperature as well as provide lubrication simultaneously. It also decreases the effect of cutting forces. Water was used for centuries as a cooling medium to assist various metal working operations. It considers that the allowable cutting speed was increased by 30 to 40 percent under the heavy stream water flooding application in the cutting zone. It was found that, although water is an excellent coolant due to its high thermal capacity and availability, the use of water as a coolant had the drawbacks of Corrosion of parts and machines and poor lubrication. After this, minerals oil were developed as a alternate of water because of their high lubricating properties however their low cooling capability and high costs restricted their use to low cutting speed operations .Later on with the development of soluble oils the machining performances were improved. Now a day's great variety of metal working fluids are available.

The Cutting fluid reduces the Cutting temperature and friction at tool chip interface by its cooling and lubrication action if and only if it has been applied in metered quality and quantity. Flood lubrication has been used since the need of cooling in the machining was arises. At the beginning (1945), the main attention was focused on minimizing the heat for better machining performance rather than flow rate, cost, disposal and environmental impact of cutting fluid. But today flood lubrication has been becoming objectionable due to its negative effects on environment, health, machining performance and water resources because of higher flow rate of petroleum based cutting fluid. In this technique high flow 
rate of cutting fluids leads to environmental degradation like soil pollution, water pollution, health hazards and most important wastage disposal of cutting fluids. Recycling cost in case of flood lubrication also require addition set up which adds in cooling cost of flood lubrication. This result in major concern regarding the disposal of metal working industries which affects the operator's health imposes pressure on the researchers to work more in this area regarding this problem.

Today's machining scenario is facing competitiveness, environment strict rules and demands higher production volume, better product quality as well as economical machining. So it is challenging task for the researcher to machine the product with a process which should be environment friendly, economical and have better quality of machining at higher cutting speed. So as achieve this target different cooling and lubrication have been developed today like Cryogenic cooling, cooling with nano particles, near dry machining(NDM) or Minimum quantity lubrication (MQL), High pressure coolant(HPC) and completely dry machining. All these techniques have their own merit and demerits depend upon the different machining operation. The cryogenic cooling and cooling with nano particles have better machining performance as compared to conventional flood lubrication, but these techniques are costlier, so there use is limited. Several developing countries have banned the use of flood lubrication and dry machining is major concern due environmental friendly behaviour. Different researchers have also mentioned that dry machining has also been limited up to particular machining parameters levels and materials. Because during dry machining of harder material at higher cutting speed leads to higher cutting temperature which effect the tool life as well as product quality.

A new technique related to conventional flood lubrication has been reported two decade ago which is filling the gap between Conventional flood lubrication and Dry machining. In this technique reduced quantity cutting fluid assisted with pressurized air jet is used, controlled, regulated and focused on Tool chip cutting area. This technique is known as Minimum Quantity lubrication, near dry machining, Spatter lubrication, near dry lubrication, micro lubrication and reduced quantity lubrication by different researcher. Minimum quantity lubrication refers to the use of cutting fluids of only a minute amount - typically of a flow rate of 50 to $500 \mathrm{ml} /$ hour - which is about three to four orders of magnitude lower than the amount commonly used in flood cooling condition, where, for example, up to 10 liters of fluid can be dispensed per minute. Minimum quantity lubrication (MQL) is based on the principle that a drop of liquid is split by an air flow, distributed in streaks and transported in the direction of flow of air. In MQL machining, a small amount of vegetable oil or biodegradable synthetic ester is sprayed to the tool tip with compressed air. The consumptions oil in industrial applications is in the range of approximately $10-500 \mathrm{ml}$ per hour.
The Present experimentation has been conducted to compare the performance Mineral oil and vegetable oil using minimum quantity lubrication. The main aim of this study is to find out the effectiveness and suitability of vegetable oil as compared to mineral oil. Different researchers has conducted studies on machining performance of mineral oil using minimum quantity lubrication but very less studies has been reported on vegetable oil minimum quantity lubrication. On the other hand there are also various hazardous effects of mineral oil reported by different researchers because of its non biodegradable nature. Therefore Vegetable oil has been selected for present investigations because of bio-degradable, environmental friendly and lubricity nature.

In 1992, Horkos Corporation [11] developed the semi dry machining of cast iron parts by combining the outside method and the outside nozzle. Research was carried out for the applications to difficult cut machining.

Byrne and Scholta [3] states that the costs related to cutting fluids are frequently higher than those related to cutting tools. Consequently, eliminating use of cutting fluids, if possible, can be a significant economic incentive.

Heisel Uwe. et al [10] has applied Minimum Quantity Cooling Lubrication Technology in Cutting Processes and concluded that there are possibilities of application of minimum quantity cooling lubricating systems in machining with geometrically defined cutting edges.

According to a survey conducted by the European Automobile Industry, the cost incurred on lubricants comprises nearly $20 \%$ of the total manufacturing cost Autret and Liang [2].The cost of the cutting tool is only $7.5 \%$ of the total cost. Hence, the Cooling cost is significantly higher. As a result, the need to decrease cutting fluid consumption is strong.

Dhar, N.R et al [7] has experimentally investigated the effect of Minimum Quantity of Lubrication (MQL) by vegetable oilbased cutting fluid on machinability of steel, the result obtained from this study using uncoated carbide tool i.e. MQL systems enabled reduction in average chip-tool interface temperature up to $10 \%$.

Dhar N. R. et al [5] has studied the effects of MQL on temperature, force, tool wear and product quality in turning AISI 9310 steel and experimental results shows that MQL with the present technique has reduced flank wear and cutting forces by about $5 \%$ to $15 \%$. Surface finish and dimensional accuracy has been improved mainly due to reduction in friction at tool chip interface by the application of MQL.

Dhar et al [6] has experimentally investigated the Effect of Minimum Quantity Lubrication (MQL) on Tool Wear, Surface Roughness and Dimensional Deviation in Turning of AISI4340 Steel, result obtained from this investigation suggested 
that MQL machining is better than that of dry and conventional flood cutting because MQL provides the benefits mainly by reducing the cutting temperature, which improves the chip-tool interaction and maintains sharpness of the cutting edges.

Rao D. Nageswara [16] has studied the influence of solid lubricant particle size on machining parameters in turning. It has been concluded that the results obtained from the experiment show the effectiveness of the use of the solid lubricant as a viable alternative to dry and wet machining. The unique utility of solid lubricant is highlighted.

Sharma Vishal S. et al [17] has suggested the Cooling techniques for improved productivity in turning. It overview the major advancement in techniques as minimum quantity lubrication (MQL)/near dry machining (NDM), high pressure coolant (HPC), cryogenic cooling, compressed air cooling and use of solid lubricants/coolants. These techniques have resulted in reduction in friction and heat at the cutting zone, hence improved productivity of the process. A brief survey of modeling/FEA techniques is also performed.

Abhang L.B et al [1] has experimentally investigated the performance of MQL machining of alloy steel with $10 \%$ boric acid by weight mixed with SAE- 40 base oil during turning of EN-31 steel using tungsten carbide cutting tool. Minimum quantity lubricant has reduced the chip-tool interface temperature by 20 to $30 \%$ in this study.

Kuram E. et al [14] has studied the Effects of the Cutting Fluid Types and Cutting Parameters on Surface Roughness and Thrust Force on AISI-304 austenitic stainless steel with HSSE tool with raw and refined sunflower oil and two other commercial cutting fluids for evaluation of thrust force and surface roughness during drilling of AISI 304 stainless steel and experimentally observed that Lower thrust force values were obtained with SCF-I and the least thrust force was achieved at spindle speed of $720 \mathrm{rpm}$. at a feed rate of 0.12 $\mathrm{mm} / \mathrm{rev}$.

Ozcelik Babur et al [15] has conducted investigations on vegetable based cutting fluids with extreme pressure during turning of AISI 304L.It has been concluded that $8 \%$ of EP included canola based cutting fluid performed better than the rest.

Cetin M. Huseyin et al [18] has investigated on Evaluation of vegetable based cutting fluids with extreme pressure and cutting parameters in turning of AISI 304L by Taguchi method. it concluded that Performances of VBCFs and commercial CFs are also compared and results generally show that sunflower and canola based CFs perform better than the others.
Hasib Md. Abdul.et al [9] has studied on Mist Application of Cutting Fluid. It concluded that the mist application enables reduction of the turning zone temperature up to $10 \%$ to $40 \%$ more than conventional methods depending on the process parameter and the mist condition provides minimum tool wear

Hadad M.J [8] has experimentally investigated the temperature and energy partition in minimum quantity lubrication during grinding operation having 100Cr6 as a work material. The temperature has been measured by embedded $\mathrm{K}$ type thermocouple. The experimental result has proved that the MQL grinding by oil has reduced the $7-10 \%$ energy as compared to dry grinding.

The review of the literature suggests that minimum quantity lubrication provides several benefits in machining as compared to Conventional flood lubrication and dry machining. The Present experimentation has been conducted to compare the performance Mineral oil and vegetable oil using minimum quantity lubrication. The main aim of this study is to find out the effectiveness and suitability of vegetable oil as compared to mineral oil.

\section{EXPERIMENTAL INVESTIGATIONS}

Experiments have been carried out by plain turning of $48 \mathrm{~mm}$ diameter and $600 \mathrm{~mm}$ long rod of EN-31 steel on powerful and rigid lathe (KIRLOSKAR, INDIA, 5HP) at different cutting velocities and feeds under dry and minimum quantity lubrication (MQL) conditions. The machinability characteristic of work material mainly in term of surface roughness has been investigated by two different cutting fluids. The ranges of the cutting parameters have selected based on the basis of tool manufacturer recommendation mentioned in their catalogues and as per industrial expert advices. The surface roughness has been measured by Talysurf surface roughness tester during different machining conditions and different cutting fluids for the comparison purpose. The Experimentations have been conducted in two different phases. In first phase the Surface roughness performance of dry machining conducted by different cutting inserts at constant feed rate and depth of cut has been compared with the surface roughness obtained during MQL with vegetable oil at same cutting conditions. In second phase the different Cutting Fluid performance conducted with MQL environment has been compared. The details of Experimental cutting conditions for both phases have given in the table 1-3. 


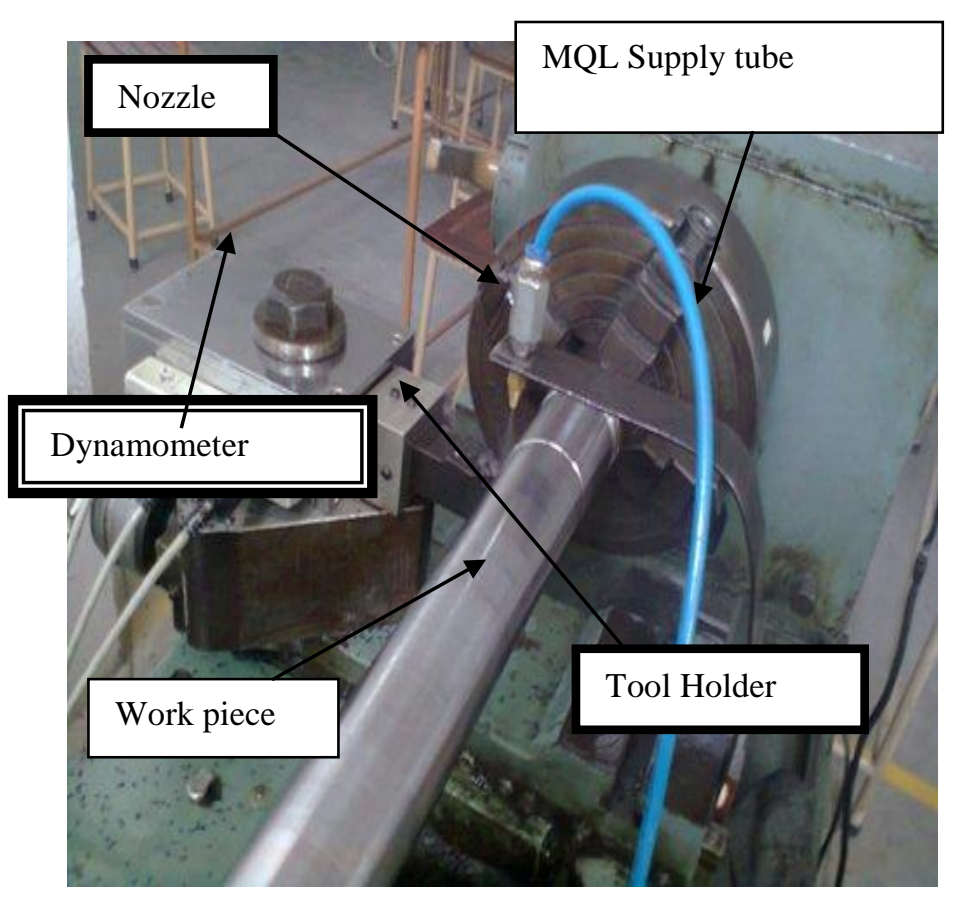

Fig-1: Photographic view of Experimental set up

Table-1: Detail of experimental Set up

\begin{tabular}{|c|c|c|}
\hline $\begin{array}{l}\text { Sr } \\
\text { No }\end{array}$ & Item & Description \\
\hline 1 & Machine Tool & $\begin{array}{l}\text { Lathe Machine } \\
\text { ( Kirloskar, INDIA) } 5 \mathrm{hp}\end{array}$ \\
\hline 2 & Work Specimen & $\begin{array}{l}\text { EN-31 Alloy Steel, Size: } \varphi 48 \\
\text { X } 600 \mathrm{~mm}\end{array}$ \\
\hline 3 & Cutting tool (insert): & $\begin{array}{l}\text { SNMG120408, CNMG120408 } \\
\text { and CNMG120412 }\end{array}$ \\
\hline 4 & Tool holder & $\begin{array}{l}\text { PSDNN 2525M12, PCBNR } \\
2525 \mathrm{M} 12\end{array}$ \\
\hline 5 & $\begin{array}{l}\text { Working tool } \\
\text { geometry }\end{array}$ & $\begin{array}{l}-7^{0},-7^{0}, 7^{0}, 7^{0}, 45^{0}, 45^{0}, 0.8 \\
\mathrm{~mm} \&-7^{0},-7^{0}, 7^{0}, 7^{0}, 75^{0}, 15^{0}, \\
1.2 \mathrm{~mm}\end{array}$ \\
\hline 6 & Cutting velocity & $1.20-2.88 \mathrm{~m} / \mathrm{s}$ \\
\hline 7 & Feed rate & $0.088,0.112$ and $0.168 \mathrm{~mm} / \mathrm{rev}$ \\
\hline 8 & Depth of cut & 0.5 and $1 \mathrm{~mm}$ \\
\hline 9 & $\begin{array}{l}\text { Cutting } \\
\text { Environments }\end{array}$ & $\begin{array}{l}\text { Dry and MQL having } \\
\text { Vegetable Oil (Soybean oil) } \\
\text { and Mineral oil at } 5 \text { bar } \\
\text { pressure }\end{array}$ \\
\hline 10 & $\begin{array}{l}\text { Distance of } \\
\text { nozzle }(\mathrm{mm})\end{array}$ & $\begin{array}{l}35 \mathrm{~mm} \text { targeted at rake face of } \\
\text { tool }\end{array}$ \\
\hline 11 & $\begin{array}{l}\text { Surface Roughness } \\
\text { tester }\end{array}$ & $\begin{array}{l}\text { Talysurf -MITUTOYO } \\
\text { JAPAN }\end{array}$ \\
\hline 12 & Air Compressor & Single phase motor driven \\
\hline
\end{tabular}

Table-2: Detail of first phase experimentation

\begin{tabular}{|c|c|c|c|}
\hline $\begin{array}{c}\text { Sr } \\
\text { No }\end{array}$ & $\begin{array}{c}\text { Cutting } \\
\text { Speed(m/s) }\end{array}$ & Insert Type & $\begin{array}{c}\text { Cutting } \\
\text { Environment }\end{array}$ \\
\hline 1 & 1.20 & SNMG120408 & Dry \\
\hline 2 & 1.86 & SNMG120408 & Dry \\
\hline 3 & 2.88 & SNMG120408 & Dry \\
\hline 4 & 1.20 & SNMG120408 & MQL \\
\hline 5 & 1.86 & SNMG120408 & MQL \\
\hline 6 & 2.88 & SNMG120408 & MQL \\
\hline 7 & 1.20 & CNMG120408 & Dry \\
\hline 8 & 1.86 & CNMG120408 & Dry \\
\hline 9 & 2.88 & CNMG120408 & Dry \\
\hline 10 & 1.20 & CNMG120408 & MQL \\
\hline 11 & 1.86 & CNMG120408 & MQL \\
\hline 12 & 2.88 & CNMG120408 & MQL \\
\hline 13 & 1.20 & CNMG120412 & Dry \\
\hline 14 & 1.86 & CNMG120412 & Dry \\
\hline 15 & 2.88 & CNMG120412 & Dry \\
\hline 16 & 1.20 & CNMG120412 & MQL \\
\hline 17 & 1.86 & CNMG120412 & MQL \\
\hline 18 & 2.88 & CNMG120412 & MQL \\
\hline
\end{tabular}

Table-3: Detail of Second phase experimentation

\begin{tabular}{|c|c|c|c|c|}
\hline $\begin{array}{l}\mathbf{S} \\
\mathbf{r} \\
\mathbf{N} \\
\mathbf{o}\end{array}$ & $\begin{array}{c}\text { Cutting } \\
\text { Speed( } \\
\mathbf{m} / \mathbf{s})\end{array}$ & $\begin{array}{c}\text { Feed } \\
\text { Rate } \\
(\mathbf{m m} / \mathbf{r e} \\
\mathbf{v})\end{array}$ & Insert Type & $\begin{array}{c}\text { Cutting } \\
\text { Environment } \\
\text { Dry \& MQL }\end{array}$ \\
\hline 1 & 1.15 & 0.088 & SNMG12040 & Vegetable Oil \\
\hline 2 & 1.78 & 0.088 & SNMG12040 & Vegetable Oil \\
\hline 3 & 2.76 & 0.088 & SNMG12040 & Vegetable Oil \\
\hline 4 & 1.15 & 0.112 & SNMG12040 & Vegetable Oil \\
\hline 5 & 1.78 & 0.112 & SNMG12040 & Vegetable Oil \\
\hline 6 & 2.76 & 0.112 & SNMG12040 & Vegetable Oil \\
\hline 7 & 1.15 & 0.168 & SNMG12040 & Vegetable Oil \\
\hline 8 & 1.78 & 0.168 & SNMG12040 & Vegetable Oil \\
\hline 9 & 2.76 & 0.168 & SNMG12040 & Vegetable Oil \\
\hline 1 & 1.15 & 0.088 & SNMG12040 & Mineral Oil \\
\hline 1 & 1.78 & 0.088 & SNMG12040 & Mineral Oil \\
\hline 1 & 2.76 & 0.088 & SNMG12040 & Mineral Oil \\
\hline 1 & 1.15 & 0.112 & SNMG12040 & Mineral Oil \\
\hline 1 & 1.78 & 0.112 & SNMG12040 & Mineral Oil \\
\hline 1 & 2.76 & 0.112 & SNMG12040 & Mineral Oil \\
\hline 1 & 1.15 & 0.168 & SNMG12040 & Mineral Oil \\
\hline 1 & 1.78 & 0.168 & SNMG12040 & Mineral Oil \\
\hline 1 & 2.76 & 0.168 & SNMG12040 & Mineral Oil \\
\hline
\end{tabular}




\section{RESULTS AND DISCUSSIONS}

In this present study MQL with Soybean oil has been used for cooling and lubrication purpose because Conventional cutting fluid application (flood lubrication) fails to cool and lubricate the tool as effectively as required because the fluid particles does not reaches in cutting zone where cooling is required, but scatter nearby area thus reduces its cooling ability. So there must be a medium which push these fluid particle towards the cutting zone for increasing cooling and lubrication ability. That's why air mixed with cutting fluid has been used for cooling and lubrication in present application of MQL with vegetable oil. During experimentation surface roughness has been measured in both environments like dry and MQL. In first phase experimentation cutting speed, Cutting inserts and cutting environments has been changed and surface roughness is measured in each case. The surface roughness results obtained from first phase experimentation has been plotted in the form of graphs. Second phase has been conducted in Dry \& MQL environments by changing cutting speed and Feed rate. The Surface roughness results of Vegetable oil and Mineral oil has been compared in this phase. The Experimental results shows that..

i. As the cutting speed increases the surface roughness decreases because of more cutting temperature, plastic deformation at tool chip interface. This high cutting temperature tends to soften the material ahead of cutting tool means easily cutting (Lower cutting forces) as compared to lower cutting speed.

\subsection{Comparison of Surface roughness in Different}

\section{Cutting Environments and Inserts}

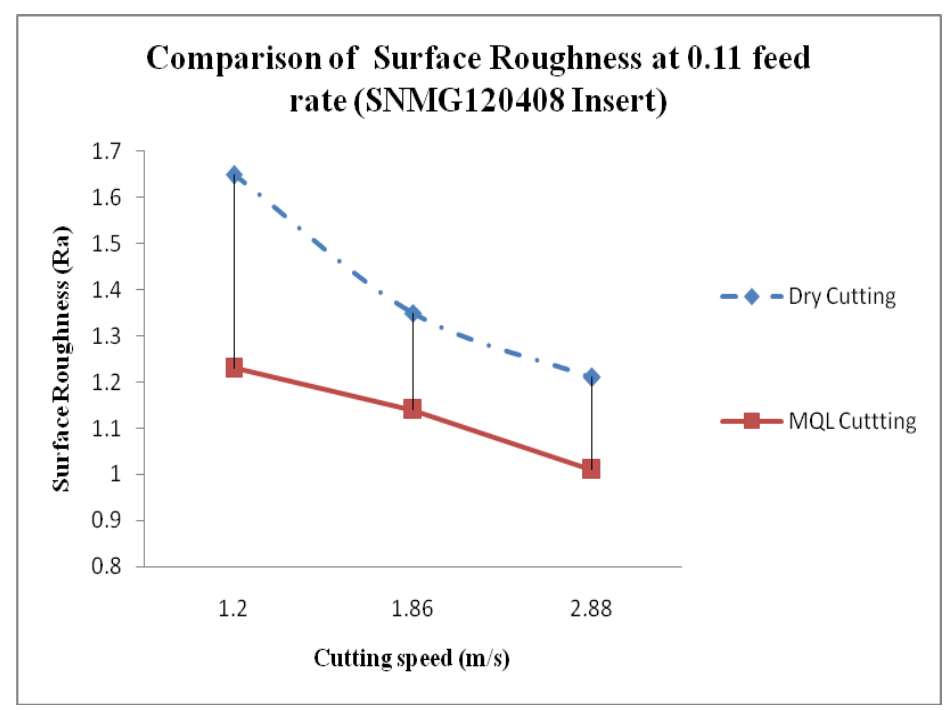

Fig- 2: Comparison of Dry and MQL Surface roughness in SNMG120408 insert at $1 \mathrm{~mm}$ doc

\section{Comparison of Surface Roughness at 0.11 feed rate (CNMG120408 Insert)}

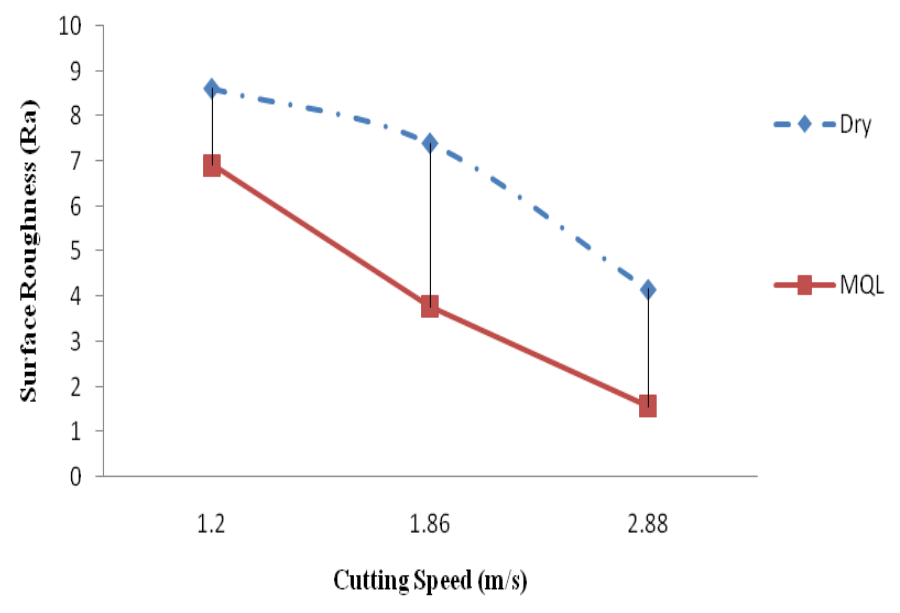

Fig -3: Comparison of Dry and MQL Surface roughness in CNMG120408 insert at $1 \mathrm{~mm}$ doc

ii. As the feed rate increases the surface roughness increases which is due to increase in chip load on cutting tool and chip thickness during cutting operation.

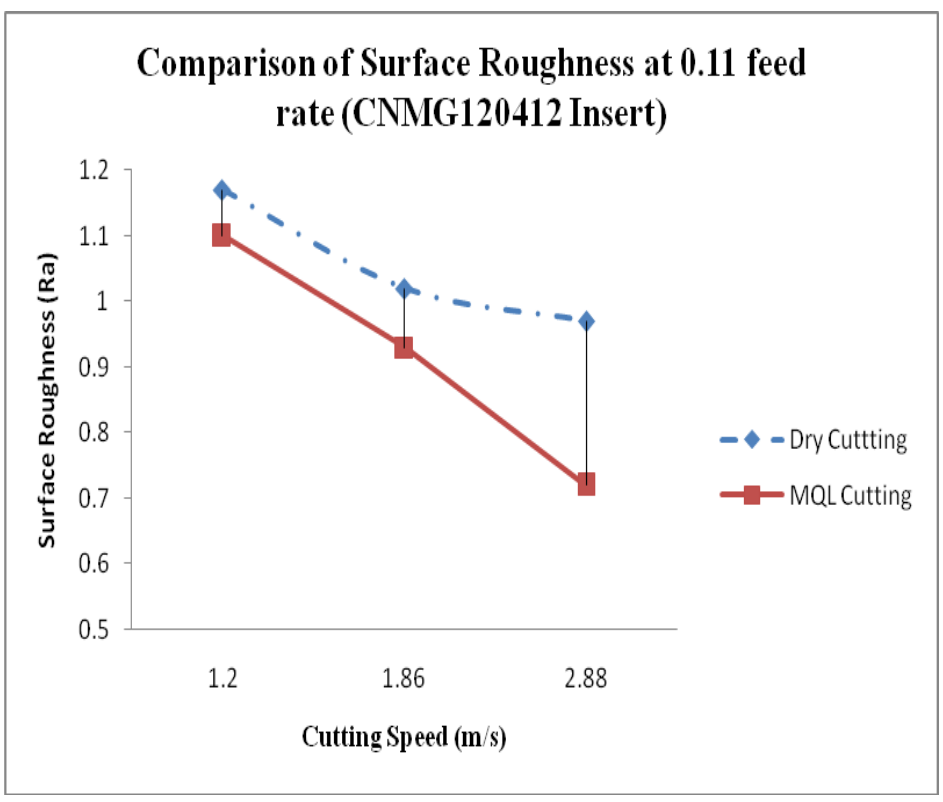

Fig 4 Comparison of Dry and MQL Surface roughness in CNMG120412 insert at $1 \mathrm{~mm}$ doc

iii. There is considerable difference between surface roughness of dry and MQL environment. The major difference has been reported in CNMG120408 cutting insert. 
iv. Better surface roughness has been reported in CNMG120412 insert during MQL.

v. MQL in present investigation has reduced the surface roughness by $20-40 \%$ as compared to dry machining during different cutting conditions.

\subsection{COMPARISON OF SURFACE ROUGHNESS} IN VEGETABLE OIL AND MINERAL OIL-

As it is clear from fig 8, the surface roughness of Vegetable oil is less or sometimes equal to the surface roughness of mineral oil. This indicates that the vegetable oil can also be used as a lubricant. This is mainly possible due to lubricity action of vegetable oil and cooling action of air mixed with it.

As shown in Fig 5-6, at speed of 1.78 and $2.7 \mathrm{~m} / \mathrm{s}$ almost same values has of surface roughness has been recorded during feed rate of $0.168 \mathrm{~mm} / \mathrm{rev}$.

\subsection{EFFECT OF NOSE RADIUS ON SURFACE ROUGHNESS IN DIFFERENT CUTTING ENVIRONMENTS}

Nose radius is an important parameter which effect Cutting Forces, Surface roughness and tool life so therefore this important parameter has also been included in this present study by taking inserts of different nose radius. CNMG120408

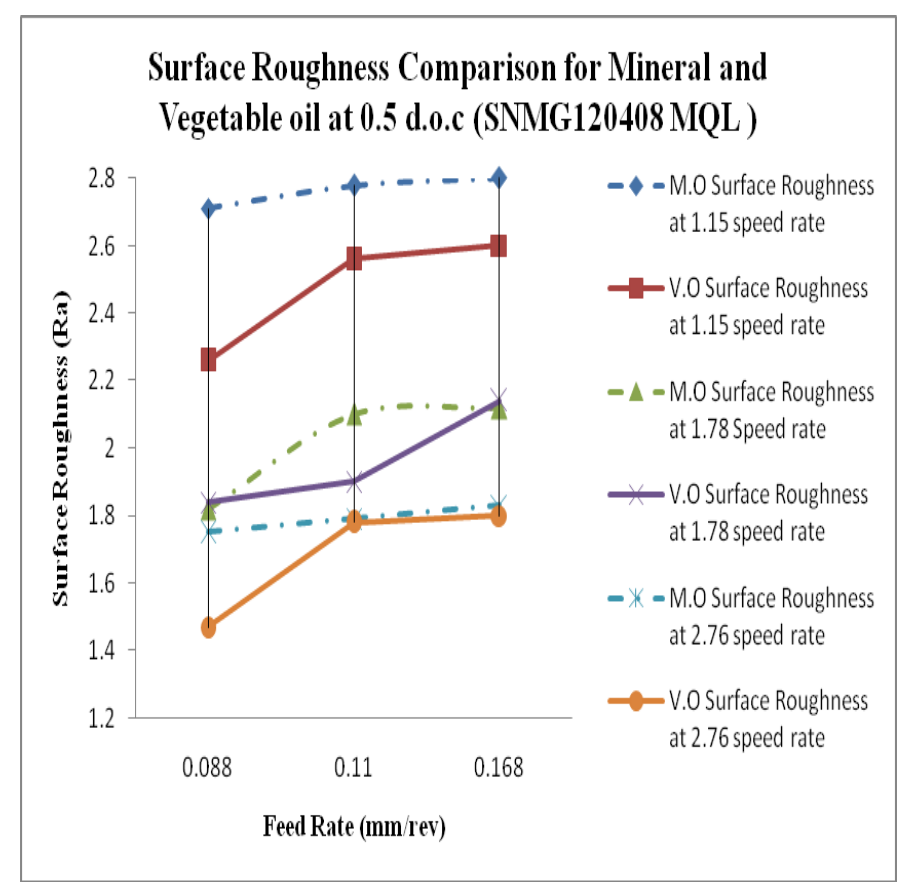

Fig 5 Comparison of Vegetable oil and Mineral oil Surface roughness

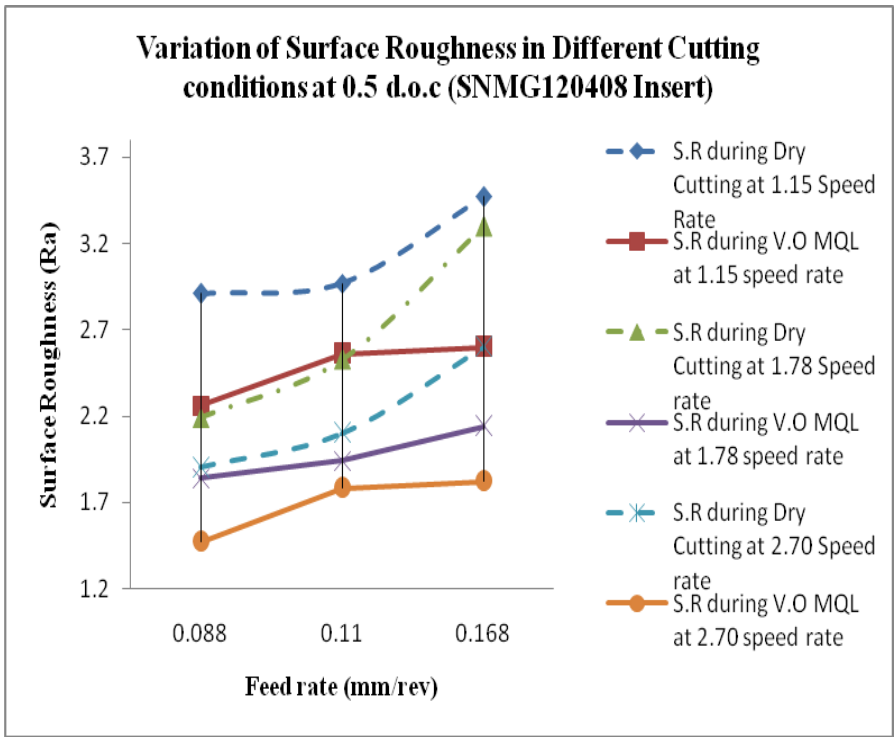

Fig 6 Comparison of Dry and Vegetable oil MQL Surface roughness

cutting insert has nose radius of $0.8 \mathrm{~mm}$ and CNMG120412 insert has niose radius of $1.2 \mathrm{~mm}$. The last two digit of Insert coding indicates the nose radius.

From fig 7, it is clear that CNMG120412 has less surface roughness as compared to CNMG120408. As the cutting speed increases the gap of surface roughness between two inserts decreases.

Again in case of MQL Environment the better results of surface roughness has been obtained as compared to dry cutting shown in fig 8 .

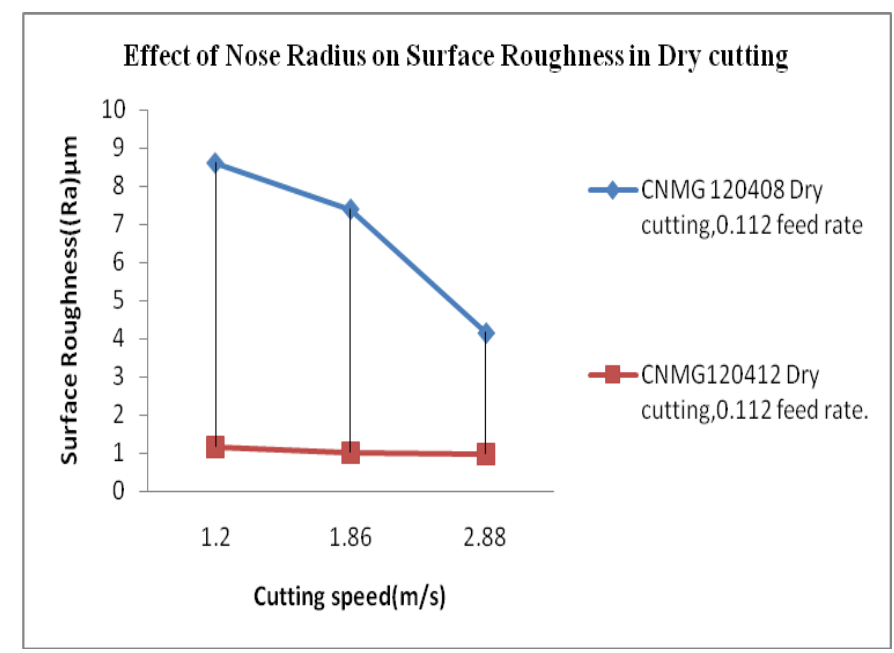

Fig 7 Effect of Nose radius on Surface roughness in Dry cutting at $1 \mathrm{~mm}$ doc 


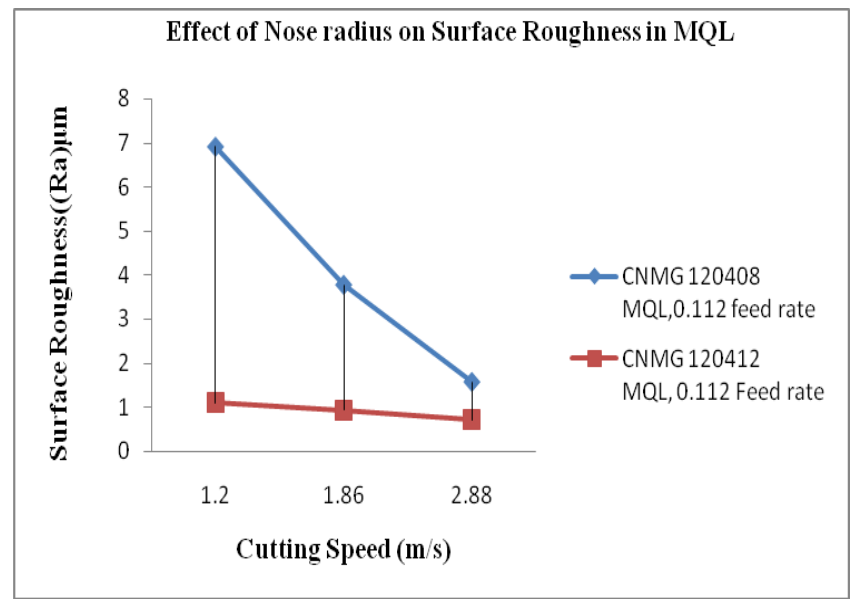

Fig 8 Effect of Nose radius on Surface roughness in MQL cutting at $1 \mathrm{~mm}$ doc

\section{CONCLUSIONS}

The main objectives of present investigation were to compare the performance of Vegetable and Mineral performance in terms of Surface roughness by using Different cutting environments and different cutting inserts at different cutting parameters. The effect of nose radius on surface roughness in dry and MQL cutting environment has also been presented in this study. The results of Surface roughness obtained during dry and MQL cutting has also been compared for exploring the role of MQL. The Experimental results confirms that

i. The Surface roughness results obtained by using Vegetable oil are within close proximity to that of Mineral oil. There is hardly difference of 1-10\%. Experimental investigations show that vegetable oil has some times better results than mineral oil in terms of surface finish.

ii. As the Cutting Speed increases the difference between surface roughness of vegetable oil and mineral oil decreases.

iii. As the Nose radius increases the surface roughness decreases due to better rounding of cutting insert. For finishing operation larger nose should be selected.

iv. MQL in present investigations has reduced the Surface roughness by $20-40 \%$ as compared to dry machining. Least Surface roughness has been reported in CNMG120412 insert during MQL.

v. Better results of surface roughness in case of MQL may be possible due to cutting \& healing, Evaporative cooling, lubricity and hydrogen embrittlement action of Vegetable based cutting fluid.

vi. MQL by vegetable oil also protects environment pollution by discharging minute amounts of fumes, mist, oxides as compared to mineral oil which is non biodegradable.

\section{REFERENCES}

[1] Abhang, L B., Hameedullah, M., "Experimental Investigation of Minimum Quantity lubricants in Alloy Steel Turning",. International Journal of Engineering Science and Technology, Volume 2(7), 2010, pp. 3045 $-3053$.

[2] Autret, R. and Liang, Y. (2003), "Minimum Quantity Lubrication in Finish Hard Turning", Georgia Institute of Technology, Atlanta, Georgia, USA.

[3] Byrne, G., and Scholta, E., "Environmental clean machining processes strategic approach". Annals of the CIRP, Vol.42 (1), 1993, pp. 471-474.

[4] Chaudhary, S. M. A., Dhar, N. R. and Bepari, M. M. A. (2007)."Effect of Minimum Quantity Lubricant on Temperature Chip and Cutting Force in Turning Medium Carbon Steel". International Conference on Mechanical Engineering, ICME (2007), December 2007.

[5] Dhar, N.R and Khan, M. M. A., (2006), "A study of effects of MQL on temperature, force, tool wear and product quality in turning AISI 9310 steel". Net Field wise Seminar on Manufacturing and Material Processing, issue 2,pp. 2006, 30-35

[6] Dhar, Nikhil Ranjan., Islam, Sumaiya and Kamruzzaman, Mohammad., "Effect of Minimum Quantity Lubrication (MQL) on Tool Wear, Surface Roughness and Dimensional Deviation in Turning AISI-4340 Steel" G.U. Journal of Science". Volume 20(2), 2007,pp. 23-32.

[7] Dhar, N. R., Islam, M. W. (2005), "The influence of Minimum Quantity of Lubrication (MQL) by vegetable oil-based cutting fluid on machinability of steel". International Conference on Mechanical Engineering, Pages 1-5.

[8] Hadad, M.J., Tawakoli, T., Sadeghi, M.H., and Sadeghi, B., "Temperature and energy partition in minimum quantity lubrication-MQL grinding process". International Journal of Machine Tools \& Manufacture, Vol. 54-55,2012, pp.10-17

[9] Hasib, M. Abdul., Al-Faruk Abdullah, Ahmed Naseem; "Mist Application of Cutting Fluid" International Journal of Mechanical \& Mechatronics Engineering IJMME-IJENS Vol: 10 No: 04.pp-13-18.

[10] Heisel, Uwe., Lutz, Stuttgart Marcel., Spath, Dieter., Wassmer, Robert., and Ulrich, Walter. "Application of Minimum Quantity Cooling Lubrication Technology in Cutting Processes". Production Engineering Vol. 2(1), 1994, pp. 49-54.

[11] Horkos Corporation,www.horkos.co.jp/english/mql.

[12] Kamruzzaman, M. and Dhar, N.R."The Effect of Applying High-Pressure Coolant (HPC) Jet in Machining of 42CRMO4 Steel by Uncoated Carbide Inserts". Journal of Mechanical Engineering, Volume 39 (No. 2), 2008, pp.71-77. 
[13] Klocke, F. and Eisenblatter, G. (1997), "Dry cutting", Annals of the CIRP, 1997, Vol. 46.(2), pp.19-526.

[14] Kuram, E., Ozcelik, B., Demirbas E and Sik, E. (2010), "Effects of the Cutting Fluid Types and Cutting Parameters on Surface Roughness and Thrust Force". Proceedings of the World Congress on Engineering, Volume II, July 2010.

[15] Ozcelik, Babur., Kuram.Emel., C.M. Huseyin and Demirbas. Erhan., "Experimental investigations of vegetable based cutting fluids with extreme pressure during turning of AISI 304L". Tribology International. Vol- 44, 2011, pp-1864-1871.

[16] Rao, D. Nageswara., Krishna. P. Vamsi., "The influence of solid lubricant particle size on machining parameters in turning". International Journal of Machine Tools \& Manufacture ,48, 2008, pp- 107-111.

[17] Sharma,V.S., Dogra, Manu., and Suri, N.M., "Cooling techniques for improved productivity in turning". International Journal of Machine Tools \& Manufacture 49 2009, .pp- 435-453.

[18] Cetin, M. Huseyin., Babur, Ozcelik., Emel, Kurama., and Erhan Demirbas.,"Evaluation of vegetable based cutting fluids with extreme pressure and cutting parameters in turning of AISI 304L by Taguchi method." Journal of Cleaner Production.Vol-19. 2011, pp-2049-2056.

\section{ACKNOWLEDGMENTS}

The work presented in this paper is the outcome of thesis done by the first author during Master of Technology (Production Engineering) Degree under the guidance of Second author. The authors are thankful to faculty and staff of Guru Nanak Dev Engineering College, Ludhiana (India) for support and encouragement.

\section{BIOGRAPHIES}

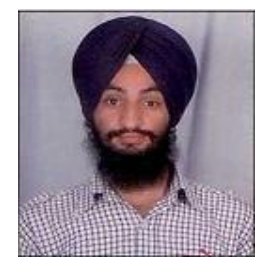

Gurpreet Singh is Currently Working as a Lecturer in Department of Mechanical Engineering at Rayat Polytechnic College, Rail Majra, Punjab, India. He has obtained his $M$ Tech degree in Production Engineering from PTU Jallandhar. He has published numbers of papers in National and International Conferences.

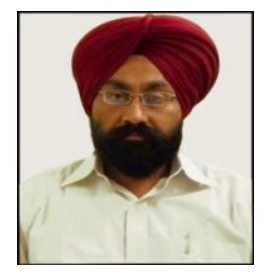

Sehijpal Singh is Currently Working as Professor and Head in Department of Mechanical Engineering at Guru Nanak Dev Engineering College, Ludhiana. He has vast teaching experience and Published numbers of papers in international, national Journals and conferences. His area of research is Non Traditional Machining, Metal machining and Advanced Manufacturing processes.

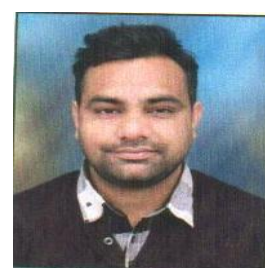

Manjot Singh is a Post Graduate Student in Production Engineering at Guru Nanak Dev engineering College, Ludhiana. After completing his B.Tech currently he is doing M.Tech in Production Engineering at Guru Nanak Dev engineering College, Ludhiana, India.

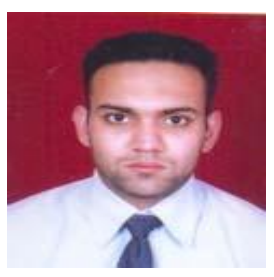

Ajay Kumar is currently working as Lecturer in Department of Mechanical Engineering at Rayat Polytechnic College, Rail Majra, Punjab. After completing his B.Tech in Mechanical Engineering, currently he is doing M.Tech at Beant College of Engineering and Technology, Gurdaspur (India). 